\title{
Gamma-ray spectroscopy measurements and simulations for uranium mining
}

\author{
T. Marchais, B. Pérot, C. Carasco, P-G Allinei, P. Chaussonnet, J-L Ma, H. Toubon
}

\begin{abstract}
AREVA Mines and the Nuclear Measurement Laboratory of CEA Cadarache are collaborating to improve the sensitivity and precision of uranium concentration evaluation by means of gamma measurements. This paper reports gamma-ray spectra, recorded with a high-purity coaxial germanium detector, on standard cement blocks with increasing uranium content, and the corresponding MCNP simulations. The detailed MCNP model of the detector and experimental setup has been validated by calculation vs. experiment comparisons. An optimization of the detector MCNP model is presented in this paper, as well as a comparison of different nuclear data libraries to explain missing or exceeding peaks in the simulation. Energy shifts observed between the fluorescence $\mathrm{X}$-rays produced by MCNP and atomic data are also investigated. The qualified numerical model will be used in further studies to develop new gamma spectroscopy approaches aiming at reducing acquisition times, especially for ore samples with low uranium content.
\end{abstract}

Index Terms - Nuclear measurements, gamma-ray spectroscopy, germanium detector, uranium mining, MCNP6

\section{INTRODUCTION}

Gamma logging for uranium exploration is currently based on total counting with Geiger Müller gas detectors or $\mathrm{NaI}(\mathrm{Tl})$ scintillators. However, the total count rate interpretation in terms of uranium concentration may be impaired in case of roll fronts, when the radioactive equilibrium of the natural ${ }^{238} \mathrm{U}$ radioactive chain is modified by differential leaching of uranium and its daughter elements (Th, Ra, Rn, etc.). Indeed, in the case of secular equilibrium, more than $95 \%$ of gamma rays emitted by uranium ores come from ${ }^{214} \mathrm{~Pb}$ and ${ }^{214} \mathrm{Bi}$ isotopes, which are in the back-end of ${ }^{238} \mathrm{U}$ chain. Consequently, these latter might still produce an intense gamma signal even when uranium is not present in the ore, or in smaller quantity than in the secular equilibrium. Therefore, additional gamma measurements of core samples are performed in surface with high energy resolution, high-purity germanium (HP Ge) detectors. These last allow the detection of imbalances using the ratio of different gamma lines of the ${ }^{238} \mathrm{U}$ decay chain, such as the well-know $1001 \mathrm{keV}$ of ${ }^{234 \mathrm{~m}} \mathrm{~Pa}$, one of the first daughters in the beginning of the chain. However due to the low intensity of this gamma ray $(0.84 \%)$,

Manuscript submitted on May 17, 2017. This work was supported by collaboration between CEA R\&D and AREVA Mines.

Thomas Marchais, Bertrand Pérot, Cédric Carasco, Pierre-Guy Allinei, Pascal Chaussonnet and Jean-Luc Ma are with CEA, DEN, Cadarache, Nuclear Measurement Laboratory, F-13108 Saint-Paul-Lez-Durance, France.

Hervé Toubon is with AREVA Mines, F-92084 Paris La Défense Cedex, Herve
France. its detection in ore samples of a few hundred grams with a low uranium concentration may require measurement times of several hours. Therefore, we plan to use more intense peaks at lower energy, such as self- fluorescence $\mathrm{X}$ rays of uranium, to reduce acquisition times. Fluorescence is induced by the main gamma radiations emitted in the ore by ${ }^{214} \mathrm{~Pb}(242,295$, $352 \mathrm{keV}),{ }^{214} \mathrm{Bi}(609 \mathrm{keV})$ and ${ }^{226} \mathrm{Ra}-{ }^{235} \mathrm{U}(186 \mathrm{keV})$. After Compton scattering, these gamma rays produce a high continuum of lower energy photons in the K-edge region of uranium $(115.6 \mathrm{keV})$, resulting in a large photoelectric absorption rate and, subsequently, in the emission of uranium fluorescence X-rays, like the most intense $98.4 \mathrm{keV}$ line. In order to study the potential of these new approaches and to establish a numerical simulation model, a measurement campaign was carried out in the radiometric calibration station of AREVA Mines in Bessines, France [1], with a coaxial HPGe detector. This station holds seven cement blocks with increasing uranium contents, up to $1 \%$ weight fraction (i.e. $10,000 \mathrm{ppm})$. The optimization of the MCNP model of the HPGe detector will be presented, as well as a comparison of different nuclear data libraries to explain missing or exceeding peaks in the simulation. Energy biases between the fluorescence X-rays produced by MCNP and atomic data will also be investigated.

\section{THE RADIOMETRIC CALIBRATION STATION}

AREVA Mines radiometric calibration station in Bessines aims to measure the counting rate due to gamma radiation emitted by seven independent cubic standard blocks with $70 \mathrm{~cm}$ edges (Fig.1). The uranium content of each block has been determined by chemical analysis (Table I). These blocks allow the calibration of radiometric probes.
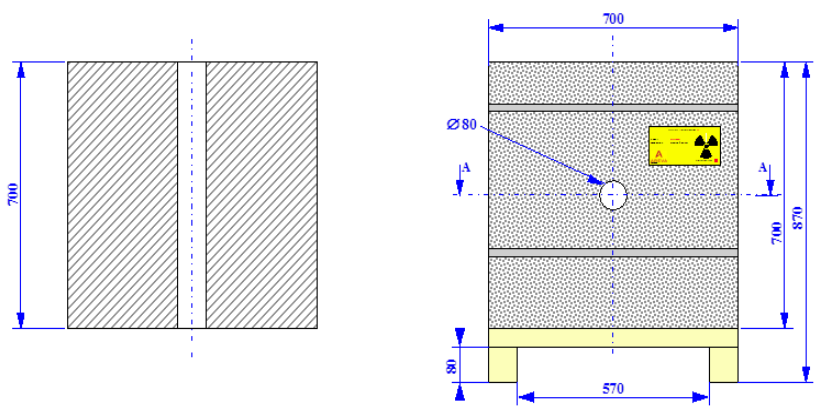

Fig. 1. Drawing of a standard block [1] 
TABLE I. CHARACTERISTICS OF THE SEVEN BLOCKS

\begin{tabular}{|c|c|c|}
\hline $\begin{array}{c}\text { Block } \\
\#\end{array}$ & $\begin{array}{c}\text { TABLE } \\
\text { fraction from } \\
\text { chemical analyses } \\
(\mathrm{ppm})\end{array}$ & $\begin{array}{c}\text { Cement density } \\
\left(\mathrm{g} . \mathrm{cm}^{-3}\right)\end{array}$ \\
\hline B1 & 0 & 1.89 \\
\hline B2 & 500 & 1.92 \\
\hline B3 & 1000 & 1.89 \\
\hline B4 & 1900 & 1.91 \\
\hline B5 & 2900 & 1.92 \\
\hline B6 & 4800 & 1.93 \\
\hline B7 & 9700 & 1.92 \\
\hline
\end{tabular}

The Nuclear Measurement Laboratory of CEA Cadarache has carried out a series of gamma-ray spectroscopy measurements on these standard blocks (Fig. 2). Results have confirmed the uranium content of each block, as shown further in Table II. The gamma spectra acquired during this campaign (Fig. 3) will also be used to validate the MCNP numerical model and to identify new information ( $\mathrm{X}$ or $\gamma$ peaks, Compton continuum, K-edge, etc.) that could be used to improve the assessment of uranium concentration. This campaign has been performed with a type $\mathrm{N}$, coaxial HPGe detector, model GR1020, CANBERRA.

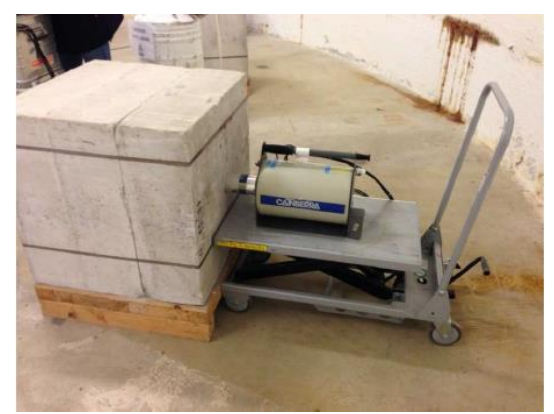

Fig. 2. Coaxial detector inside a standard cement blocks at Bessines.

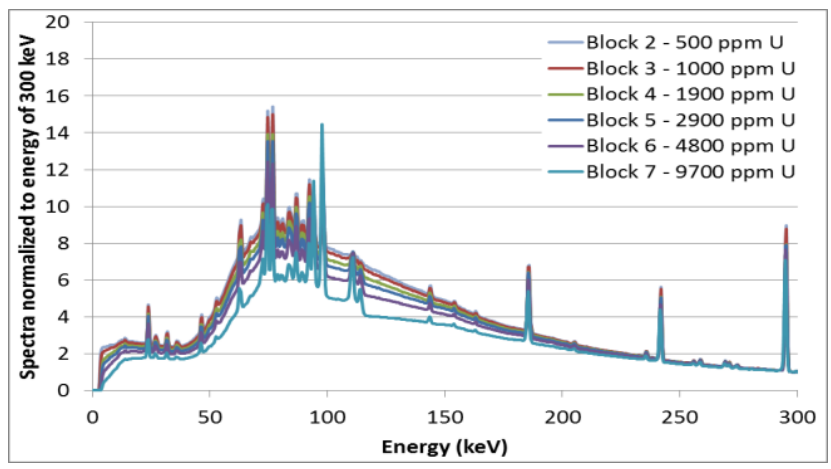

Fig. 3. Gamma-ray spectra of the seven calibration blocks of AREVA radiometric station in Bessines, France.

\section{Simulation OF THE COAXIAL DETECTOR}

The coaxial detector was modeled with the MCNP Monte Carlo computer code [2]. The geometric model of the detector is based on the manufacturer scheme, on X-ray radiography, and on measurements performed with a multi-energy beam coming from a highly collimated ${ }^{152} \mathrm{Eu}$ gamma source (see Fig. 4), which allowed to precisely estimate the position and active area of the crystal. The calculated and experimental detector efficiencies are reported in Fig. 5. The measured efficiency was built with calibration point sources $\left({ }^{241} \mathrm{Am}\right.$ $59.5 \mathrm{keV}$ line, ${ }^{109} \mathrm{Cd} 88.0 \mathrm{keV}$ peak, and ${ }^{152} \mathrm{Eu}$ gamma-rays from $121.8 \mathrm{keV}$ to $1408 \mathrm{keV}$ ) at a distance of $50 \mathrm{~cm}$ from the detector head. Note that to obtain the good agreement observed in Fig. 5, a dead layer has been implemented in the model of the germanium crystal, in the back, external edge of the germanium cylinder, to reflect a deficit of charge collection in this region. A copper electrode connecting the cooling system and the germanium crystal is also described, as well as the external aluminum cover.

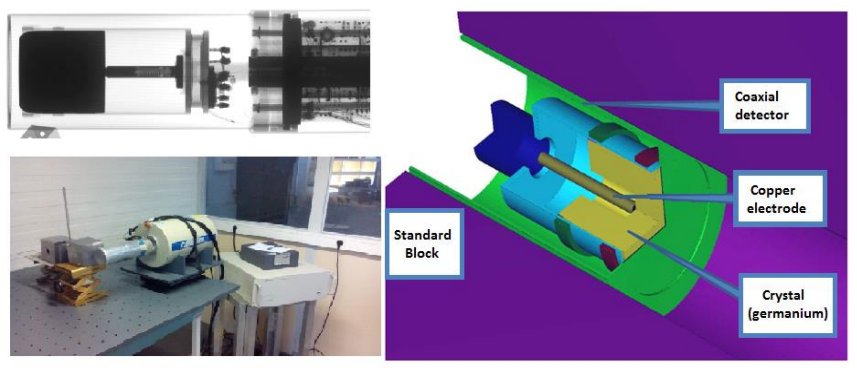

Fig. 4. X-ray radiography and the modeling of the coaxial detector.

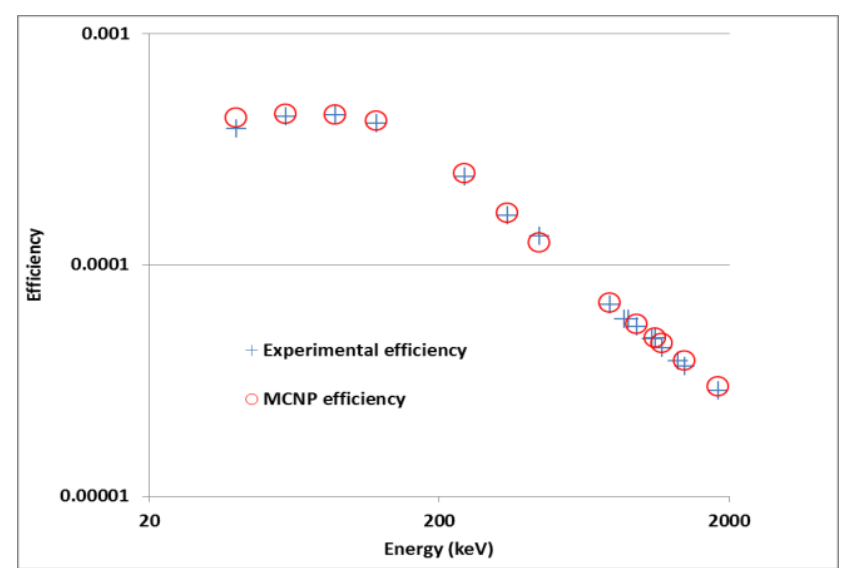

Fig. 5. Experimental and MCNP efficiency of the coaxial HPGe measured with point sources at a distance of $50 \mathrm{~cm}$ from the detector entrance face.

\section{VERIFICATION OF THE URANIUM CONTENT IN THE STANDARD CONCRETE BLOCKS}

The global detection efficiency, including self-absorption in the standard cement blocks, has been calculated with MCNP with a first objective to determine the uranium mass concentration of each block, using the ${ }^{234 \mathrm{~m}} \mathrm{~Pa}$ gamma ray at $1001 \mathrm{keV}$. Equation (1) allows converting the net area of this peak into uranium mass concentration ( $\mathrm{ppm}$ ).

$$
\begin{aligned}
& C m_{U}=\frac{(1+\eta) \times 10^{6} \times M_{m o l}\left({ }^{238} \mathrm{U}\right) \times T_{1 / 2}\left({ }^{238} \mathrm{U}\right)}{N_{A} \times \ln (2)} \\
& \times \frac{S_{n}(1001 \mathrm{keV})}{T c \times M_{\text {Block }} \times I_{\gamma}(1001 \mathrm{keV}) \times E f f(1001 \mathrm{keV})}
\end{aligned}
$$

With:

$\mathrm{Cm}_{U}$ : Uranium mass concentration of each block (ppm)

$S_{n}(1001 \mathrm{keV})$ : Net area of the peak at $1001 \mathrm{keV}$ measured on the gamma spectrum (number of counts, dimensionless number) 
Tc: Acquisition "live time" (i.e. real time corrected for dead time) of the gamma spectrum (s)

$I_{\gamma}(1001 \mathrm{keV})$ : Intensity of emission of the peak at $1001 \mathrm{keV}$ of ${ }^{234 \mathrm{~m} P a}(0.84 \%)$ in the ${ }^{238} \mathrm{U}$ filiation

Eff $(1001 \mathrm{keV})$ : Detection efficiency calculated with MCNP for each block (number of count in the full-energy peak at $1001 \mathrm{keV}$ per photon of $1001 \mathrm{keV}$ emitted in the block)

$T_{1 / 2}\left({ }^{238} U\right)$ : Radioactive period of ${ }^{238} \mathrm{U}(\mathrm{s})$

$N_{A}$ : Avogadro constant $\left(6,023 \cdot 10^{23}\right.$ atoms per mole, dimensionless number)

$M_{m o l}\left({ }^{238} U\right)$ : Molar mass of ${ }^{238} \mathrm{U}(\mathrm{g})$

$\eta$ : Mass fraction of ${ }^{235} \mathrm{U}$ in natural uranium $(0.72 \%)$

The mass concentration obtained by gamma-ray spectroscopy using (1) is in good agreement with chemical analysis, as shown in Table II. The reported uncertainty includes the detector calibration and modeling uncertainty (2.6\%), the statistical uncertainty on the net area of the peak at $1001 \mathrm{keV}$ (between $0.9 \%$ and $22 \%$, depending on uranium concentration), the uncertainty on the $1001 \mathrm{keV}$ gamma-ray intensity $(1.32 \%)$, the statistical uncertainty of MCNP calculations (less than $1 \%$ ), and the uncertainty of the MCNP modeling of the concrete blocks and measurement setup. Concerning this last, the main source of uncertainty concerns concrete density, which varies from 1.89 to $1.93 \mathrm{~g} . \mathrm{cm}^{-3}$ depending on the measured block. The dispersion of the efficiency values calculated on the blocks with MCNP is equal to $0.97 \%$. This value has been retained to be the uncertainty of the modeling of the measurement scene at $1 \sigma$. The global uncertainty is the quadratic sum of these uncertainties.

TABLE II. URANIUM MASS CONCENTRATIONS (PPM) OF BESSINES CALIBRATION BLOCKS MEASURED BY GAMMA-RAY SPECTROSCOPY AND

\begin{tabular}{|c|c|c|c|}
\hline \multirow{2}{*}{ Block } & $\begin{array}{c}\text { Chemical } \\
\text { analysis }\end{array}$ & $\begin{array}{c}\text { Gamma-ray } \\
\text { spectroscopy (and } 1 \sigma \\
\text { uncertainty) }\end{array}$ & $\begin{array}{c}\text { Relative } \\
\text { difference }\end{array}$ \\
\hline B1 & 0 & $2.1( \pm 22 \%)$ & N/A \\
\hline B2 & 500 & $459( \pm 3.7 \%)$ & $-8.2 \%$ \\
\hline B3 & 1000 & $958( \pm 1.9 \%)$ & $-4.2 \%$ \\
\hline B4 & 1900 & $1960( \pm 2.3 \%)$ & $3.4 \%$ \\
\hline B5 & 2900 & $2800( \pm 3.3 \%)$ & $-3.5 \%$ \\
\hline B6 & 4800 & $4550( \pm 1.8 \%)$ & $-5.2 \%$ \\
\hline B7 & 9700 & $9530( \pm 2.0 \%)$ & $-1.8 \%$ \\
\hline
\end{tabular}

\section{SIMULATION OF THE STANDARD CONCRETE BLOCKS GAMMA SPECTRA}

The simulation of the concrete blocks is based on a cement chemical composition given by AREVA Mines, including uranium concentrations (and densities) given in Table I. An isotropic gamma source uniformly distributed in the cement block is implemented in MCNP. The natural ${ }^{238} \mathrm{U}$ and ${ }^{235} \mathrm{U}$ radioactive chains are supposed in secular equilibrium. The source term retains only 14 predominant gamma emitters observed in the experimental spectra: ${ }^{238} \mathrm{U},{ }^{234} \mathrm{Th},{ }^{234 \mathrm{~m}} \mathrm{~Pa}$,
${ }^{230} \mathrm{Th},{ }^{226} \mathrm{Ra},{ }^{214} \mathrm{~Pb},{ }^{214} \mathrm{Bi},{ }^{210} \mathrm{~Pb},{ }^{235} \mathrm{U},{ }^{231} \mathrm{Th},{ }^{227} \mathrm{Th},{ }^{223} \mathrm{Ra},{ }^{219} \mathrm{Rn}$, and ${ }^{211} \mathrm{~Pb}$. The intensity and energy of each gamma ray are taken from the JEFF 3.1.1 library, and only the lines with energy larger than $40 \mathrm{keV}$ are modeled.

Fig. 6 shows a good general agreement between simulated and experimental spectra, only small differences being observed for minor peaks. For instance, the $89.5 \mathrm{keV}$ peak was initially absent from the simulated spectrum due to a missing emission line of ${ }^{214} \mathrm{~Pb}$ at $89.8 \mathrm{keV}$ in the JEFF 3.1.1 library $\left(\mathrm{Bi} \mathrm{K}_{\beta 2} \mathrm{X}\right.$ ray, intensity of $0.67 \%$ in ENSDF [3]), combined with an underestimation emission of ${ }^{214} \mathrm{Bi}$ at $89.2 \mathrm{keV}$ (Po K ${ }_{\beta 3}$ X-ray, $0.085 \%$ in JEFF 3.1 .1 instead of $0.116 \%$ in ENSDF [3]). After implementing ENSDF data [3], the calculated $89.5 \mathrm{keV}$ peak was found in satisfactory agreement with experiment (Fig. 7).

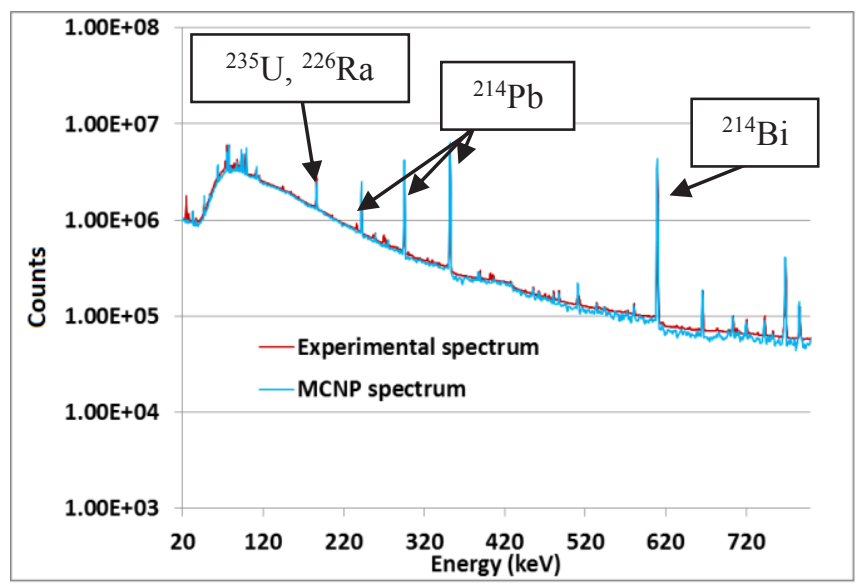

Fig. 6. Experimental and MCNP spectra of block B5 using ENSDF database.

We can also note in Fig. 7 that a peak is missing in the simulation at $110.4 \mathrm{keV}$, in the broad bump including both 110.4 and $111.3 \mathrm{keV}$ uranium fluorescence $\mathrm{X}$-rays $\left(\mathrm{K}_{\beta 3}\right.$ and $\mathrm{K}_{\beta 1}$, respectively [4]). Indeed, MCNP manual [5] indicates that for elements with atomic number $\mathrm{Z}>37$, the $\mathrm{X}$-ray emission $\mathrm{K}_{\beta 3}$ is not simulated, and $\mathrm{K}_{\beta 1} \mathrm{X}$-ray includes all transition intensities from layers $\mathrm{L}$ to $\mathrm{K}$, which explains the absence of the $110.4 \mathrm{keV}$ peak $\left(\mathrm{K}_{\beta 3}\right)$ and a higher intensity at $111.3 \mathrm{keV}$ $\left(\mathrm{K}_{\beta 1}\right)$.

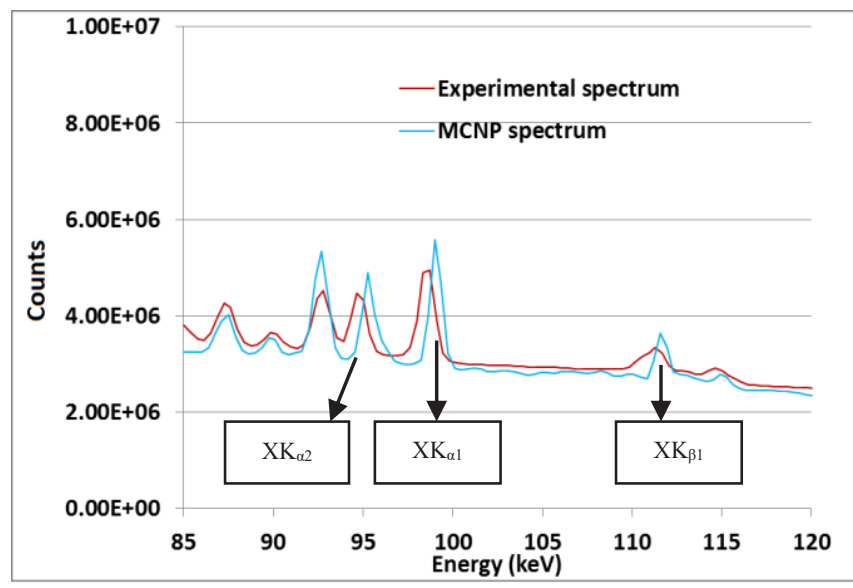

Fig. 7. Experimental and MCNP spectra of block B5 at low energy.

Fig. 7 also shows a significant energy shift between calculation and experiment concerning uranium fluorescence 
X-rays. Further investigation of the MCNP fluorescence peaks energy shift has been performed for 53 materials having atomic numbers between 40 (zirconium) and 92 (uranium) irradiated by a $1 \mathrm{MeV}$ photon beam. The energy shift between MCNP and the expected fluorescence X-ray energy shown in Fig. 8 as a function of $\mathrm{Z}$ reproduces the observation previously made in [6].

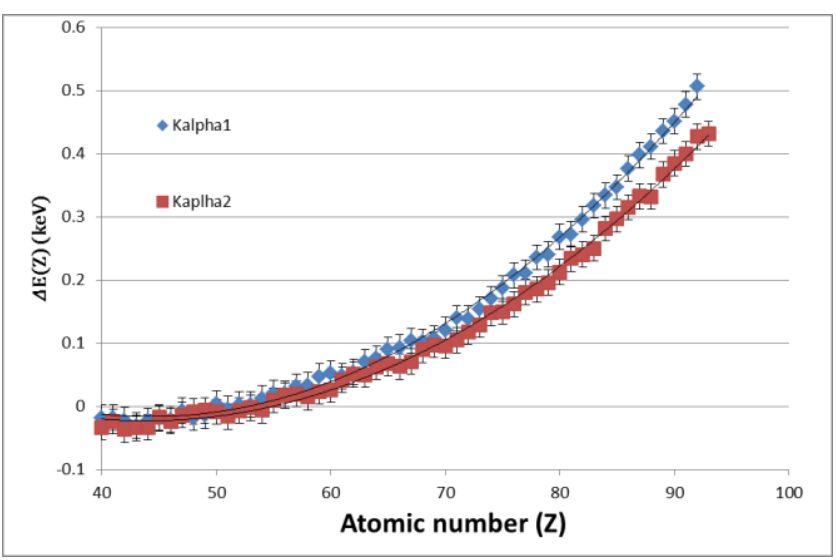

Fig. 8. Energy shift between the energy of fluorescence X-rays calculated with MCNP and the theoretical values taken from [3].

In further studies, this energy shift will be corrected when processing MCNP output data to allow a better agreement with the experimental spectrum.

\section{CONCLUSION AND PROSPECTS}

Seven calibration blocks with known uranium concentrations have been measured by high resolution gamma-ray spectroscopy at AREVA Mines calibration station, in Bessines, France, and simulated with MCNP computer code. First, a detailed model of the coaxial HPGe detector has been carried out using calibration acquisitions with standard point sources of ${ }^{109} \mathrm{Cd},{ }^{152} \mathrm{Eu}$, and ${ }^{241} \mathrm{Am}$. Then, the uranium mass concentrations of the blocks (in ppm), originally determined by chemical analysis, has been confirmed by gamma-ray spectroscopy with the $1001 \mathrm{keV}$ gamma ray of ${ }^{234 \mathrm{~m}} \mathrm{~Pa}$, in the ${ }^{238} \mathrm{U}$ radioactive chain. Finally, we obtained a very good agreement between the overall gamma spectra of the blocks calculated with MCNP and the ones measured in Bessines. Only minor discrepancies concerning small peaks have been observed and corrected, which were due to unprecise or missing nuclear data, as well as small bias in the energy of fluorescence X-rays produced by MCNP, which will be corrected in future studies.

We will now use the validated numerical model to study new gamma-ray spectroscopy methods, in view to characterize uranium faster than with the reference $1001 \mathrm{keV}$ line. Indeed, its intensity $(0.84 \%)$ leads to hours of acquisition time for ore samples of a few hundred grams with uranium concentration lower than $1 \%$ mass fraction. Among the information that is not yet used, uranium self-fluorescence X-rays in the $100 \mathrm{keV}$ region ( $\mathrm{K}_{\alpha}$ and $\mathrm{K}_{\beta}$ transitions) can be detected in a much shorter time. They are induced by gamma radiations of the ore itself and could be used to characterize uranium up to a depth of several centimeters, hence being appropriate for small ore samples.

\section{REFERENCES}

[1] http://www.areva.com/EN/operations-598/bessines-a-standardsettingindustrial-facility

[2] MCNP6TM, User's manual - Version 1.0 - LA-CP-13-00634, Rev. 0 May 2013 - Denise B. Pelowitz, editor

[3] The Lund/LBNL Nuclear Data Search, Version 2.0, February 1999, S.Y.F. Chu, L.P. Ekström and R.B. Firestone, LBNL, Berkeley, USA, and Lund University, Sweden, http://nucleardata.nuclear.lu.se/toi/

[4] M.C. Miller, X-ray Fluorescence, Chapter 10 of Passive Nondestructive Assay of Nuclear Materials (1991) pp. 313-335, NUREGCR5550, Los Alamos National Laboratory.

[5] Morgan C. White, Los Alamos National Laboratory, Los Alamos, "Photoatomic Data Library MCPLIB04: A New Photoatomic Library Based On Data from ENDF/B-VI Release 8" - LA-UR-03-1019- Dec. 2002.

[6] Cook, Matthew Tyler, "Hybrid K-edge Densitometry as a Method for Materials Accountancy Measurements in Pyrochemical Reprocessing." PhD diss., University of Tennessee, 2015. http://trace.tennessee.edu/utk graddiss/3329

[7] Gordon GILMORE, John HEMINGWAY - "Practical gamma-ray spectrometry" - 1995

[8] T. Jensen, T. Aljundi, C. Whitmore, H. Zhong, and J. N. Gray, "X-Ray, K-Edge Measurement of Uranium Concentration in Reactor Fuel Plates," Ames Lab., IA (United States), IS--5129, Nov. 1997, http://dx.doi.org/10.2172/671994

[9] P. Pin and B. Perot, "Characterization of Uranium in Bituminized Radioactive Waste Drums by Self-Induced X-Ray Fluorescence," IEEE Trans. Nucl. Sci., vol. 61, no. 4, pp. 2131-2136, Aug. 2014. 